\title{
Why should we care about academic integrity in nursing students?
}

\author{
Elizabeth Emmanuel ${ }^{* 1}$, Jann Fielden ${ }^{1}$, Kolleen Miller-Rosser ${ }^{2}$ \\ ${ }^{1}$ School of Health and Human Sciences, Southern Cross University, Gold Coast Campus, Queensland, Australia \\ ${ }^{2}$ School of Health and Human Sciences, Southern Cross University, Coffs Harbour Campus, New South Wales, Australia
}

Received: December 16, 2020

DOI: $10.5430 /$ jnep.v11n5p46
Accepted: January 21, $2021 \quad$ Online Published: January 25, 2021

URL: https://doi.org/10.5430/jnep.v11n5p46

\begin{abstract}
Integrity, honesty, and respect are essential values for nursing students. Yet, in recent years the rise of breaches in academic integrity has become alarming. The era of increasing advances in the capabilities of smart technologies may be facilitating rather than deterring students from academic integrity breaches in their work and assessments. This issue raises questions for nurse academics on how they can best ensure that nursing students align their behavior with the expected nursing's professional values, both during their study years and beyond. This discussion paper aims to examine contributing factors leading to breaches of academic integrity amongst nursing students and determine why we as nurse academics need to both remain alert to these factors, and vigilant about identifying and managing such breaches. Existing factors that may influence academic dishonesty are discussed concerning students; nurse academics; curriculum design; and the apparently growing cultural shift in ethical reasoning. With increased insight into these influencing factors, nurse academics need to take responsibility and prepare students to take on the highest standard of moral values to ensure safe and effective patient outcomes. We need to become more aware of and understand nursing students' perspectives and adequately prepare our soon-to-become nurse graduates. We are charged with supporting, guiding, and teaching our students to develop skills within a culture of integrity. Ensuring an integrity activity smorgasbord in our practice can counteract the increased risk of academic dishonesty in our undergraduate nursing programs.
\end{abstract}

Key Words: Academic integrity, Nursing students, Ethical reasoning, Practice, Technology, Curriculum

\section{INTRODUCTION}

Moving away from in-class writing assessments and increased availability of online resources, have over the past decade, contributed to a surge in questionable integrity of students' work. For Higher Education institutions, the issue has now become a global priority. ${ }^{[1]}$ Concerning the nursing profession and nursing education, the core values of honesty and integrity embedded in the Code of conduct for nurses ${ }^{[2]}$ and the ICN Code of ethics for nurses ${ }^{[3]}$ are being challenged. A review of the literature by Lynch et al. ${ }^{[4]}$ has shown that various forms of academic cheating are prevalent among nursing students. For many students, the understanding of what it means to be dishonest in their assessments is not clear. As such, there have been several studies examining the topic of academic integrity focusing on nursing students in general. The increase in breaches of academic integrity is disquieting for nurse academics. A better understanding of both what constitutes academic integrity breaches and approaches to identifying and managing potential and actual breaches are needed. This discussion paper aims to determine why

\footnotetext{
*Correspondence: Elizabeth Emmanuel; Email: elizabeth.emmanuel@scu.edu.au; Address: School of Health and Human Sciences, Southern Cross University, Gold Coast Campus, Southern Cross Drive, Bilinga QLD 4225, Australia.
} 
nurse academics need to remain alert to contemporary factors contributing to academic integrity issues amongst nursing students. Honesty and integrity are important and essential values throughout the academic and clinical education of nursing students. Greater emphasis on first-year nursing students would provide a unique opportunity to shape nursing students into their professional roles and build on these basic values.

\section{Phenomenon of aCAdemic dishon- ESTY}

Academic integrity can be defined as acting with honesty, respect, trust, fairness and responsibility when producing academic work. ${ }^{[5]}$ Academic dishonesty is when deceitful ways are used, consciously or unconsciously, which ultimately gives one an unfair advantage. Examples of academic dishonesty include 'plagiarism, collusion, copying and cheating' (p. 11). ${ }^{[6]}$ Indeed, Academic dishonesty is not considered a new phenomenon in the modern era. ${ }^{[7,8]}$ The phenomenon is well documented throughout the literature. Historically it has been stated that the first rule of writing is that one should not take another's work as their own, and that what they write should be their own work. ${ }^{[9]}$ Academic dishonesty predates the computer and internet and can be traced back to the turn of the 20th century. ${ }^{[8]}$ Fass-Holmes ${ }^{[10]}$ identified that literature regarding academic dishonesty can be dated back to the early 1900s. While Patton and Purdie ${ }^{[11]}$ identified that during the 20th century breaches in academic integrity were not as prevalent as they are in the 21 st century.

Furthermore, technological advances have increased the capabilities of mobile devices (smartphones, watches, tablets, IPads), giving instant access to the internet for literary sources of information, and third-party sources to complete student assessments (contract cheating). ${ }^{[12]}$ This easy accessibility may inadvertently lead to the assumption that what is online is not copyrighted by anyone. This extent of cheating is now a bigger problem than it was in the past. ${ }^{[11]}$ More recently, with the move to online examinations for students, academics report a further increase in cheating. ${ }^{[13,14]}$ Such behavior can become regularized to become part of the student culture in this 21 st century. ${ }^{[15]}$ Harris et al. ${ }^{[16]}$ identified the rise of the new cheating economy as being that of commercialized websites that market themselves as providing "study help".

The dilemmas for nurse academics are many. These include how they ensure student accountability against the many temptations or learned behaviors surrounding academic dishonesty. How do nurse academics decide who is truly sitting the online examination or collaborating with others? To answer such questions, nurse academics need to get to the heart of the problem and understand what are the influencing factors that challenge basic nursing values. Nurse academics need to understand that entering the tertiary system and taking responsibility for one's learning, can be challenging for students. Many students are unclear about academic integrity and unaware of the implications of plagiarism or collusion. For instance, students are of the mindset that showing their essay to friends is being helpful, and therefore may not fully understand the issues associated with academic dishonesty. ${ }^{[17]}$

\subsection{Origin of integrity}

The term, integrity is derived from Ancient Roman times, when soldiers of good character were given armored breastplates protecting their heart, signifying that their allegiance was strong and that they had wholeness and strength of character. ${ }^{[18]}$ Integrity is a moral compass that enables people to be true to their values and beliefs and live by these. In short, it is about doing the right thing for themselves, and others. ${ }^{[19]}$ In a similar manner, today integrity is the armor that protects and guides nurses when faced with various challenges at work and in life. Therefore, in the eyes of patients, teachers, colleagues, and families, it is expected that nurses will have such traits as honesty and trustworthiness. In the current context of the fast-expanding information age, with fake news and fabrications, ${ }^{[20]}$ the need for integrity has become even more important. For nursing students, these concepts are introduced in their foundational degree program. Linked to these are the attributes of honesty, ethical behavior, trust and mutual respect within the learning environment of the classroom and clinical field. ${ }^{[21]}$ The growing incidence of academic dishonesty should serve as a flag for nurse academics to factors impacting academic integrity and determine an approach that would better prepare soon to-become nurse graduates.

\subsection{Why nurse academics need to remain alert to issues impacting academic integrity}

We need to recognize several important aspects that could benefit the academic integrity issues. Firstly, it is the responsibility of nurse academics to prepare nursing students for practice in a manner that aligns with the Standards of Practice, and with values embedded in the ICN Code of Ethics for Nurses. ${ }^{[3]}$ Secondly, preparing students appropriately increases the longevity within the workforce. ${ }^{[22]}$ Thirdly, the consistent contact that nurse academics have with students during this critical period of study facilitates role modeling and learning opportunities. Therefore, it is imperative that the issues of academic dishonesty are examined, and that the influencing factors that exacerbate breaches of academic 
integrity are identified to establish a way forward. Collectively, nurse academics need to appreciate that academic integrity is not only fundamental to learning and teaching, but also imparts a significant value to students, faculty and the nursing profession. Nurse academics need to understand why, when faced with competing needs to succeed, some students find an easier way out by cutting corners. ${ }^{[23]}$ The notion of conscience needs to come into play, whereby students take responsibility towards maintaining personal and professional values and standards. ${ }^{[24]}$ As reported by Birks et al., ${ }^{[25]}$ plagiarism and other forms of cheating are on the rise. Therefore, nurse academics must look much more broadly than just integrity and honesty.

\subsection{The current situation}

Issues with academic integrity occur across all year levels within the undergraduate nursing program. There is a greater focus on the first-year experience as it is a significant period in a student's life. During this time, many students are committed, motivated, and persist in achieving their goals. ${ }^{[26]}$ Along the way, students are also learning in new environments and meeting life challenges which can make the transition into tertiary studies difficult. ${ }^{[27]}$ The learning encounters include issues such as unmet expectations, limited academic writing skills, discontent with the learning/teaching environment, ${ }^{[28]}$ and lack of understanding or clarity as to what is required in an assessment item. Life encounters may be comprised of health or stress issues, work-life-study demands leading to low prioritization of study, financial strain, and an increasing study workload. ${ }^{[29]}$ However, the need and pressure to succeed, and student perceptions of inadequate marker attention to, and application of policies ${ }^{[13,30]}$ can lead students along a pathway of finding the quickest and easiest ways of meeting assessment deadlines and requirements ${ }^{[14]}$

In recognition of these evolving complexities impacting students, the Higher Education Standards Panel, ${ }^{[31]}$ recommended that universities prioritize enabling students in achieving the "best chance to complete their studies through the appropriate provision of academic and other support services" (p. 9). Therefore, many universities in Australia have instigated a variety of resources to support and guide students, generally with an all-purpose approach. Their aim is to support students in being mindful of ensuring that they adhere to the values of academic integrity; develop their academic writing in an authentic way, utilize various resources to increase awareness; avoid academic cheating behaviors by following policies; and being aware of applied consequences when breaches do occur. ${ }^{[30]}$ Common resources include fact sheets, workshops, quizzes, online learning modules, and guidance from both academic and support staff including librarians and learning and teaching advisors. Despite these measures, studies have shown that increased knowledge and understanding do little to deter academic cheating across different age groups and over time. ${ }^{[32,33]}$ Thus, it is essential that we understand further what the contributing factors are, for change to occur.

\section{Contributing Factors relating to BREACHES IN ACADEMIC INTEGRITY}

\subsection{Students}

Uppermost in the preparation to become a nurse, students learn about the requirements for them to engage with the highest standards of ethics and conduct in order to ensure safe patient care. However, a national cross-sectional study by Birks et al., ${ }^{[25]}$ reports concerning results on academic dishonesty among nursing students. At least half of nursing students acknowledged academic and professional misconduct during their undergraduate study. A study by Brimble and Stevenson-Clarke ${ }^{[34]}$ surveying students across four Australian universities, identified that cheating occurs for several reasons. These reasons include: perceiving an assessment item as being too complex, time-consuming; when two or more assessments are due simultaneously; wanting to help student colleagues; lack of understanding of core academic writing skills such as citing direct quotations, paraphrasing and referencing, and plagiarism; and believing that they are unlikely to be found out. Another study by Brimble ${ }^{[30]}$ pointed out other reasons including a) the perception that if their peers can get away with cheating, then they might as well cheat too; b) if they cheated previously without being caught they are more likely to cheat again, and; c) that penalties imposed by the university are minimal. While, a more recent study by Bailey ${ }^{[35]}$ identified specific student characteristics that led to cheating. These included: a) students with poor adherence to ethical standards as they mostly wanted to get the assessment completed and did not want to engage in the learning process presented by the assessment item; $b$ ) students with poor time management, who procrastinate or experience stress or mental health issues; and c) vulnerable students giving in to peer pressure to share their assessment.

About demographic characteristics of students, two Australian studies ${ }^{[28,36]}$ found that younger, male, those studying engineering, and linguistically diverse students were more likely to cheat in assessments. In the first study by Bretag et al., ${ }^{[28]}$ linguistically diverse students more frequently plagiarised in their work. Although the reliance on self-report of cheating behaviors creates a risk of response bias, there are key messages for nurse academics. These messages are that students are likely to cheat if they spoke a language other than English at home; they believed that there are many occasions 
to cheat; or feel dissatisfied with the learning environment. In contrast, the second study a Kremmer et al. ${ }^{[36]}$ found that students tended to cheat if they previously engaged in cheating.

Other contributing factors included feeling disconnected from university staff and peers, for instance with the move to online learning during the COVID-19 pandemic, and a low value placed on skills of academic writing. Mostly, this is related to an underestimation of the importance of academic writing skills, and confusion about the academic expectations within assessments. ${ }^{[37]}$ Additionally, with pressures to balance paid work and personal responsibilities alongside study demands, students are more likely to seek unpaid help from others. ${ }^{[38]}$ Access to digital media and resources on the internet is another factor enabling cheating behaviors. For instance, during un-invigilated online exams, students may access information on the internet, communicate with peers or even have someone else undertake the exam for them. ${ }^{[13]}$ The recent proliferation of academic cheating services provides a further temptation for some students to outsource all or part of an assessment (contract cheating). To prevent such services, the Australian government passed legislation making it an offense to advertise or make academic cheating services available in higher education. ${ }^{[39]}$

\subsection{Nurse academics}

Role modeling by nurse academics is important for students' personal and professional development. Many feel this is an obligation to ensure a sound learning experience for nursing students while maintaining their own commitment to the nursing profession. Additionally, society needs to be assured that graduating students are safe and knowledgeable as they provide care for patients. ${ }^{[40]}$ Having standards of practice that are vague or when there are recurring negative learning experiences, may be confusing for students. ${ }^{[41]}$ This can occur when the educator does not openly and regularly emphasize the need for standards of professionalism. ${ }^{[42]}$ For instance, there are many reasons why nurse academics are reluctant to refer a student for breaches of academic integrity, e.g. pressures in meeting required course objectives; providing soft marking and grade inflating to improve student evaluation of teaching, increasing workloads of academics as a result of convoluted processes of the reporting system, all of which appear to be encroaching into yearly performance reviews. ${ }^{[43,44]}$

Although universities have academic integrity policies and procedures which clearly identify potential breaches, other important factors may be at play, which indirectly or directly deter the follow-up of identifying and reporting or managing cheating behaviors. For example, anecdotally it appears that the granting of extensions for student assessments has increased enormously in recent times. Bretag et al. ${ }^{[28]}$ suggest that the extra time granted for extensions, could potentially promote reliance on peers, family, and outsourcing of the assignment to a paid service, in order to meet the deadlines. However, it would be difficult to ascertain, as further evidence in different contexts is needed to support this view.

The need for quality and careful auditing within universities puts pressure on academics. Academics themselves have been found wanting where integrity is concerned. A good example is a reliance on student evaluations, used to measure student satisfaction with and the effectiveness of teaching by academic staff. Although evidence suggests that ratings from many student evaluation tools are unreliable and ratings often invalid, ${ }^{[45,46]}$ university management frequently use these ratings, during annual staff performance reviews, to assist with making decisions about continued employment (tenure) and promotion for academics. ${ }^{[44]}$ Consequently, the potential for academics to be lenient with assignment scoring and inflating final grades in order to secure high evaluation ratings may occur.

The increasing casualization of academics may also have an impact on managing breaches of academic integrity. Lama and Joullie ${ }^{[47]}$ posed the question regarding teaching quality being at risk due to the large proportions of casual academics in Australian Universities. It is reported that up to $80 \%$ of undergraduate courses are being taught by casual staff. ${ }^{[48]}$ With this level of casualization is the concern that casual staff may not have a vested interest in identifying and reporting student breaches in academic integrity. Furthermore, they may not have a good understanding of university policies and procedures regarding reporting academic dishonesty.

\subsection{Curriculum design}

The university landscape and culture are undergoing rapid change. The changes permeate through to curriculum design and its implementation. As a result, increased commercialization, mass production, reliance on digital technology, sense of disconnection with students, dwindling resources, and contracted study periods have been identified as influencing quality teaching. These influences provide an ideal setting that lends itself towards tolerating cheating behaviors and attitudes. ${ }^{[30]}$ Furthermore, it is reported that many academics are disenchanted with teaching and increased demands and make up for this by overlooking learning issues and being quiet about these. ${ }^{[44]}$ However, Bretag ${ }^{[1]}$ identified that academics differed in their perspectives related to academic integrity, leading to a lack of consistency in identifying and reporting/managing breaches of academic integrity. With the rise in breaches, the need for nurse academics to ensure they 
comply with university screening strategies and measures to follow up and manage breaches remains paramount. ${ }^{[48]}$ Nevertheless, financial constraints in designating enough workload for staff to oversee potential/actual breaches are also problematic. Thus, as universities become more constrained, cheating is more likely to continue.

Academic dishonesty has also been strongly associated with assessment design. A national study by Bretag et al., ${ }^{[49]}$ which involved 14,086 responses from 8 Australian universities, identified student dissatisfaction that centered on trying to make sense of assessment requirements, insufficient feedback, and limited assistance and support from staff. It is hardly surprising, therefore, that students seek help from third parties to complete their assessment. Indeed, Bretag et al. ${ }^{[23]}$ reported in their survey that many students said low awareness of academic integrity and its related policy and did not feel confident about avoiding breaches. Despite the availability of online educational resources about academic integrity, deterrence measures, and penalties that may be incurred, it would seem that students do not entirely take advantage of information resources. An alternative approach is needed, firstly to address the concerns students have as highlighted in Bretag et al.'s collection of work, ${ }^{[28,49,50]}$ rather than focus on deterrence and punitive measures.

One crucial concern is the embedded perception in the curriculum that 'one size fits all'. Today, many university settings have student cohorts from diverse backgrounds, circumstances, and experiences, and it could be postulated that little consideration is given to this diversity among student cohorts. ${ }^{[51]}$ Their ability to gain and synthesize information frequently depends on their dominant language and access to information. However, many curricula do not consider the diversity of learners' characteristics. Students differ in the way they take in and make sense of data. Their personal experiences come into play, as well as their place in the world and social identity. Besides, students have their preferences for learning, strengths, and weaknesses. Should they come from a non-dominant and non-English language background, there is a struggle to access and interpret information in a meaningful manner. Therefore, the exclusive nature of existing curricula can create barriers to a positive learning experience and entice students to find alternative ways to deal with assessments.

\subsection{Cultural shift in ethical reasoning}

There is a cultural shift in ethical reasoning with a corresponding increase in student acceptance of what has traditionally been considered cheating behaviors in their academic work. ${ }^{[30,52]}$ Balik et al. ${ }^{[53]}$ suggest that cheating behaviors may reflect the general social decline in public morals within society's broader context. Similarly, Brimble ${ }^{[30]}$ argues that there are numerous and growing instances of 'political corruption, corporate fraud' (p. 366) and economic scandals in the broader society, which over time, may de-sensitize people, leading to increased acceptance of such behaviors. Consequently, such cultural shifts may influence students to become more accepting of plagiarism and other cheating behaviors and they may rationalize such behavior in terms of "effort versus grade" pay-off and the perception that "others cheat so why not me" (p. 367). Harkins and Kubik ${ }^{[54]}$ introduce the idea of 'ethical cheating' whereby in the context of an ever-increasingly digitized world characterized by ready access to information, students can "rapidly formulate new digital cultures with new rules that determine their behaviors, boundaries, and values" (p. 142). Thus, they believe that what they are doing is acceptable. The tolerance for what academics might call cheating increases amongst students, as their ethical reasoning is relegated to the background during the study years.

There is also growing evidence that nursing and other university students who breach academic integrity values are more likely to behave unethically in the workplace. ${ }^{[55,56]}$ Carter et al. ${ }^{[55]}$ emphasize that "The reputation and integrity of the profession begins in the classroom and extends into the clinical environment" (p. 5), further claiming that students who plagiarise in their academic assessments may well take this habit into their clinical practice upon graduation. For instance, writing generic patient notes for several patients is considered 'false documentation'. In turn, when dishonesty carries over into the workplace, it places patients at risk of harm. ${ }^{[21]}$

\section{Discussion}

The emerging literature relating to academic integrity issues has revealed a range of factors that may contribute to academic dishonesty in nursing students. Responsibility needs to be taken at all levels to reduce the conditions that could provide students with opportunities to behave dishonestly during their student years. ${ }^{[30]}$ It is the responsibility of nurse academics to assist students in extending their moral and intellectual abilities. From this perspective, the nurse academic needs to nurture the whole person, not just the educational capabilities of nursing students. ${ }^{[57]}$ Students require support, clear guidance, and teaching on developing skills within a culture of integrity. ${ }^{[23]}$ With the increasing application of smart technologies in education, the challenge to ensure that students learn to present their work with suitable acknowledgment of others' ideas remains problematic. It is indisputable that nursing students are expected to uphold the values of academic integrity. However, it is not surprising that many 
students still inadvertently breach the essential values of academic integrity in their work.

A way forward to deter breaches in academic integrity is paramount. Miller ${ }^{[58]}$ proposes that academic integrity be introduced early in tandem with literacy skills in the first year of study. Also, building a culture of integrity and providing opportunities for reflection on students' progress in academic skills acquisition and professional integrity (practice ethics) is important. This might include completing online quizzes and having access to interactive online academic integrity education that could enhance their adoption of academic skills. ${ }^{[56,57]}$

In cases where students deliberately fail to demonstrate academic integrity during their student years, evidence indicates a higher likelihood that they will also act dishonestly in the workplace. ${ }^{[56]}$ Therefore, nursing academics need to ensure that nursing curricula explicitly embeds integrity throughout the undergraduate degree program and encourage students to understand academic and professional integrity/honesty. Nursing consistently ranks at the top of all professions for ethics and honesty. Therefore, when students fail to embrace academic integrity values during their student years, the profession risks losing its status as the most trusted of all professions. ${ }^{[55,59]}$

\section{CONCLUSION/RECOMMENDATIONS}

Nursing students must have adequate opportunities to learn and practice the academic writing skills needed to ensure academic integrity. Engagement in values that align students to nursing's professional standards of practice and code of ethics, with greater emphasis in the first year, prepares them for graduation and beyond. With the increased awareness and insights, nurse academics must employ a range of strategies to counteract the increased risks associated with academic dishonesty.

These strategies compiled as an integrity activity smorgasbord include:

- Organizational/administrative strategies to educate, identify, rectify and manage intentional and unintentional breaches of academic integrity

- Role modeling (by academics) acceptable behaviors that demonstrate moral integrity

- Briefing students on the organizational policies and processes associated with academic integrity to foster transparency in expectations

- Teaching and embedding academic writing skills into the curricula

- Teaching/learning strategies to assist students to identify breaches in academic integrity

- Exercises in paraphrasing, direct quoting, and correctly referencing ideas, specifically in the first-year cohorts

- Discuss exemplars of breaches in academic integrity, such as written work or videos, with students

- Enable students to write a small piece of work and submit it to Turnitin (c) to identify similarity and originality areas, so that they are more aware of what constitutes a breach, and how breaches are identified

- Openly discussing aspects of academic integrity

To conclude, the authors propose that integrity be explicitly embedded in the curriculum as an essential learning component. In this way, the focus is more on teaching students about academic integrity than penalizing them when they err. While at the same time, nurse academics must remain vigilant about upholding integrity in undergraduate nursing programs.

\section{CONFLicts OF INTEREST Disclosure}

The authors declare that there is no conflict of interest.

\section{REFERENCES}

[1] Bretag T. Handbook of Academic Integrity. Singapore: Springer; 2016.

[2] NMBA, Code of conduct for nurses. 2018, Nursing and Midwifery Board of Australia.

[3] International Council of Nurses, The ICN code of ethics for nurses 2012: Geneva, Switzerland.

[4] Lynch J, et al. Plagiarism in nursing education: an integrative review. Journal of Clinical Nursing. 2017; 26(19-20): 2845-2864. PMid:27808468 https://doi.org/10.1111/jocn. 13629

[5] Bretag T. Challenges in Addressing Plagiarism in Education. PLoS Med. 2013.

[6] International Network for Quality Assurance Agencies in Higher Education (INQAAHE), Toolkit to support quality assurance agencies to address academic integrity and contract cheating. Government of Australia. 2020.

[7] Baird J. Current trends in College cheating. Psychology in the School. 1980; 17(4): 515-522. https://doi.org/10.1002/1520-680 7(198010) $17: 4<515:$ : AID-PITS2310170417>3.0.CO;2-3

[8] Crown D, Spiller M. Learning from the literature on collegiate cheating: A review of empirical research. Journal of Business Ethics. 1988; 17(6): $683-700$

[9] Cook T. Plagiarism and proprietary authorship in early modern England, 1590-1640 2013

[10] Fass-Holmes, B., International students reported for academic integrity violations: Demographics, retention, and graduation. Journal of International Students. 2017; 7(3): 644-669. https ://doi .org/ 10.20533/licej.2040.2589.2014.0215 
[11] Patton, B. and N. Purdie, Academic Integrity in the 21st Century. Literacy Information and Computer Education Journal. 2014; 5(3): 1617-1620

[12] Bretag T, et al. Contract cheating in Australian higher education: a comparison of non-university higher education providers and universities. Assessment \& Evaluation in Higher Education. 2020; 45(1): 125-139. https://doi.org/10.1080/02602938.2019.161414 6

[13] Dyer J, Pettyjohn H, Saladin S. Academic Dishonesty and Testing: How Student Beliefs and Test Settings Impact Decisions to Cheat. Journal of the National College Testing Association. 2020; 4(1): $1-30$.

[14] Khan Z, Subramanian S. Students go click, flick and cheat: Echeating, technologies and more. Journal of Academic and Business Ethics. 2012; 6: 1-26.

[15] Azulay Chertok I, Barnes E, Gilleland D. Academic integrity in the online learning environment for health sciences students. Nurse Education Today. 2014; 34(10): 1324-1329. PMid:23870688 https : //doi.org/10.1016/j.nedt.2013.06.002

[16] Harris L, et al. Academic Integrity in an Online Culture: Do McCabe's Findings Hold True for Online, Adult Learners? Journal of Academic Ethics. 2020; 18(4): 419-434. https ://doi .org/10.1 007/s10805-019-09335-3

[17] Thomas R. Collusion confusion with the QAA. 2012 [cited 2020; Available from: https://nouse.co.uk/2012/5/22/collusio n-confusion-with-the-qaa

[18] Stephens T. The road to purity. Setting captives free. 2012: Xlibris.

[19] MacKenzie A, Bhatt I. Opposing the Power of Lies, Bullshit and Fake News: the Value of Truth. Postdigital Science and Education. 2020; 2(1): 217-232. https://doi.org/10.1007/s42438-019 $-00087-2$

[20] Montgomery Collins E, Bassat Q. The Scientific Integrity of Journal Publications in the Age of 'Fake News'. Journal of Tropical Pediatrics. 2018; 64(5): 360-363. PMid:30053246 https : //doi .org/ 10.1093/tropej/fmy039

[21] Devine CA, Chin ED. Integrity in nursing students: A concept analysis. Nurse Education Today. 2018; 60: 133-138. PMid:29112897 https://doi.org/10.1016/j.nedt.2017.10.005

[22] Baldwin A, et al. Reconciling professional identity: A grounded theory of nurse academics' role modelling for undergraduate students. Nurse Education Today. 2017; 59: 1-5. PMid:28898727 https://doi.org/10.1016/j.nedt.2017.08.010

[23] Bretag T., et al., 'Teach us how to do it properly!' An Australian academic integrity student survey. Studies in Higher Education. 2014; 39(7): 1150-1169. https://doi.org/10.1080/03075079.201 3.777406

[24] Cleary M, Lees D. The Role of Conscience in Nursing Practice. Issues in Mental Health Nursing. 2019; 40(3): 281-283. PMid:30633604 https://doi.org/10.1080/01612840.2019.1548852

[25] Birks M, et al. Exploring the paradox: A cros sectional study of academic dishonesty among Australian nursing students. Nurse Education Today. 2018; 65: 96-101. PMid:29547814 https://doi.or g/10.1016/j.nedt. 2018.02.040

[26] Tinto V. Through the eyes of students. Journal of College Student Retention: Research, Theory \& Practice. 2017; 19(3): 254-269. https://doi.org/10.1177/1521025115621917

[27] Kift S. A decade of transition pedagogy: a quantam leap in conceptualising the first year experience. HERDAS Review of Higher Education. 2015; 2: 51-86.

[28] Bretag T, et al. Contract cheating and assessment design: exploring the relationship. Assessment \& Evaluation in Higher Education. 2019b. 44(5): 676-691. https://doi.org/10.1080/02602938 .2018 .1527892

[29] UES Consortium, 2013 University experience survey national report. 2014: Canberra.

[30] Brimble M. Why students cheat: An exploration of the motivators of student academic dishonesty in higher education, in Handbook of Academic Integrity, T. Bretag, Editor. Springer: Singapore. 2016; 365-382. https://doi.org/10.1007/978-981-287-098-8_5 8

[31] Australian Government Higher Education Standards Panel, Final report - Improving retention, completion and success in higher education. 2018.

[32] Woith W, Jenkins S, Kerber C. Perceptions of academic integrity among nursing students. Nurs Forum. 2012; 47(4): 253-9. PMid:23127239 https://doi.org/10.1111/j.1744-6198.20 $12.00274 . \mathrm{x}$

[33] Smedley A, Crawford T, Cloete L. An intervention aimed at reducing plagiarism in undergraduate nursing students. Nurse Educ Pract. 2015; 15(3): 168-73. PMid:25578380 https://doi.org/10.101 6/j.nepr.2014.12.003

[34] Brimble M, Stevenson-Clarke P. Perceptions of the prevalence and seriousness of academic dishonesty in Australian universities. The Australian Educational Researcher. 2005; 32(3): 19-44. https : //doi.org/10.1007/BF03216825

[35] Bailey J. 3 Things You Can't Teach About Plagiarism, in Plagiarism Today Newsletter. 2020.

[36] Kremmer M, Brimble M, Stevenson-Clarke P. Investigating the probability of student cheating:The relevance of student characteristics, assessment items, perceptions of prevalence and history of engagement. International Journal for Educational Integrity. 2007; 3(2) https://doi.org/10.21913/IJEI.v3i2.162

[37] Jefferies D, et al. The importance of academic literacy for undergraduate nursing students and its relationship to future professional clinical practice: A systematic review. Nurse Education Today. 2018; 60: 84-91. PMid:29055236 https : //doi .org/10.1016/j.nedt .2017 .09 .020

[38] Rogerson A, Basanta G. Peer-to-peer file sharing and acadmic integrity in the internet age, in Handbook of Academic Integrity T. Bretag, Editor. Springer: Singapore. 2016; 273-364. https: //doi.org/10.1007/978-981-287-098-8_55

[39] The Parliament of the Commonwealth of Australia, Tertiary Education Quality and Standards Agency Amendment (Prohibiting Academic Cheating Services) in Tertiary Education Quality and Standards Agency Amendment (Prohibiting Academic Cheating Services), H.o. Representatives, Editor. 2020: Canberra, ACT.

[40] Reis J, Klotz J. The road to loss of academic integrity is littered with SET: A hypothetical dilemma, in 5th Asia Pacific Conference on Educational Integrity. 2011.

[41] Kenny N, Mann K, MacLeod H. Role modeling in physicians' professional formation: reconsidering an essential but untapped educational strategy. Acad Med. 2003; 78(12): 1203-10. PMid:14660418 https ://doi .org/10.1097/00001888-200312000-00002

[42] Passi V, et al. Doctor role modelling in medical education: BEME Guide No. 27. Medical Teacher. 2013; 35(9): e1422 e1436. PMid:23826717 https://doi.org/10.3109/0142159X .2013 .806982

[43] Hornstein H. Student evaluations of teaching are an inadequate assessment tool for evaluating faculty performance. Cogent Education. 2017; 4(1): 1-8. https://doi.org/10.1080/2331186X. 2017. 1304016

[44] Eckhaus E, Davidovitch N. Potential for Blocking Advancement: Teaching Surveys for Student Evaluation of Lecturers. Interna- 
tional Journal of Educational Methodology. 2019; 5(3): 401-406. https://doi.org/10.12973/ijem.5.3.401

[45] Braga M, Paccagnella P, Pellizzari M. Evaluating students' evaluations of professors. Economics of Education Review. 2014; 41: 71-88. https://doi.org/10.1016/j.econedurev. 2014.04.002

[46] Uttl B, White C, Gonzalez A. Meta-analysis of faculty's teaching effectiveness: Student evaluation of teaching ratings and student learning are not related. Studies in Educational Evaluation. 2017; 54: 22-42. https://doi.org/10.1016/j. stueduc. 2016.08.007

[47] Lama T, Joullie J. Casualization of academics in the Australian higher education: is teaching quality at risk? . Research in Higher Education Journal. 2015; 28: 1-11.

[48] Patty A. Universities grapple with new ways to test students to combat cheating, in The Sydney Morning Herald. 2020.

[49] Bretag T, et al. Contract cheating: a survey of Australian university students. Studies in Higher Education. 2019a; 44(11): 1837-1856. https://doi.org/10.1080/03075079.2018.1462788

[50] Bretag T, et al. Contract cheating in Australian higher education: a comparison of non-university higher education providers and universities. Assessment and Evaluation in Higher Education. 2020; 45(1): 125-139. https://doi .org/10.1080/02602938.2019.161414 6

[51] Hector-Alexander A., Inclusive Curriculum Design, in Technology and the Curriculum. Ontario Tech University. 2019.
[52] Cho OH, Hwang KH. Academic ethical awareness among undergraduate nursing students. Nursing Ethics. 2017; 26(3): 833-844. PMid:28893158 https://doi.org/10.1177/09697330177271 55

[53] Balik C, et al. Attitudes towards academic cheating during nursing studies. Medicine and law. 2010; 29(4): 547-563.

[54] Harkins A, Kubik G. "Ethical" cheating in formal education. On the Horizon. 2010; 18(2): 138-146. https://doi .org/10.1108/10 748121011050487

[55] Carter H, Hussey J, Forehand JW. Plagiarism in nursing education and the ethical implications in practice. Heliyon. 2019; 5(3): e01350. PMid:30949602 https://doi .org/10.1016/j .heliyon. 2019 .e01350

[56] Moore HA, Gaviola MS. Engaging Nursing Students in a Culture of Integrity. J Nurs Educ. 2018; 57(4): 237-239. PMid:29614194 https://doi.org/10.3928/01484834-20180322-09

[57] Schwartz S. Educating the Nurse of the Future -Report of the Independent Review into Nursing Education. Commonwealth of Australia. 2019.

[58] Miller, L., Digital integrity as a 21st Century skill, in Technology and the curriculum: Summer 2019. 2019, Pressbooks.

[59] Brenan MRf. Nurses Keep Healthy lead as Most Honest, Ethical Profession. 2017. Available from: https://news.gallup.com/poll/224639/nurses-kee p-healthy-leadhonest-ethical-profession.aspx 